targeted, specific resources, with a 'one size fits all approach' being inappropriate. Continued consultations with Aboriginal community groups throughout Western Australia has assisted in finalising resources and ensuring they are relevant and appropriate for use throughout Western Australia.

\section{COMMUNITY MOBILISATION TO ESTABLISH A COMMUNITY CRECHE TO INCREASE CHILD SUPERVISION IN RURAL NEPAL}

${ }^{1}$ Puspa Raj Pant, ${ }^{2}$ Matthew Ellis, ${ }^{1}$ Toity Deave, ${ }^{1} J u l i e$ Mytton. ${ }^{1}$ University of the West of England, Bristol; ${ }^{2}$ University of Bristol

\subsection{6/injuryprev-2016-042156.699}

Background Injuries are among the leading causes of death and hospitalisation of children worldwide; $90 \%$ of all injuries are unintentional. In 2010, over 900 children aged 1-4 years died from injuries in Nepal; the extent of non-fatal injuries is unknown. Most of the injuries to younger children occur at home, and associated with lack of supervision. Community mobilisation may be a feasible approach for preventing child injuries in rural Nepal. We describe community mobilisation for developing a community-crèche for 1-3 year old children to increase supervision and promote early childhood development.

Methods We worked with one women's group in Makwanpur and facilitated group discussion; a visit to an established crèche system in Bangladesh; did debriefing and orientation, and community involvement sessions. The women's group formed a committee to develop and manage the crèche; nominating 2 volunteers who were responsible for identifying eligible children and running the crèche. Published minimum standards for early child development centres (ECDC) by the government of Nepal were applied.

Results In February 2015, a crèche was established in Hatiya (Makwanpur) under the ownership of local women's group; and registered with local authority. A qualified ECD trainer trained the volunteers and mothers on stages of childhood development. A total of 17 children aged 1-3 years were enrolled and attended the crèche for 3 to 4 hours daily. Parents observed positive changes in children attending crèche. They also felt their children were in secure place when they were at work. The local municipality provided financial support to the crèche. A local government ECD centre agreed to intake the graduates from the crèche. Conclusion It is feasible, acceptable and potentially sustainable to establish crèches for young children in Nepal with full ownership of local women's group. There is very high potential for the partnership with local government which can also provide resources.

\section{0 \\ ROAD TRAFFIC INJURIES AMONG CHILDREN ATTENDED AT ER, YANGON GENERAL HOSPITAL}

Htun Nanda, Aung Thein Htay, Thit Lwin. Department of Orthopaedics and Trauma, University of Medicine 1, Yangon

\subsection{6/injuryprev-2016-042156.700}

Background As Myanmar is moving towards the socioeconomic development more accidents are happening amid increasing number of vehicles. There were very few studies regarding with childhood injuries in Myanmar and further studies and evaluation are required to get appropriate preventive measures for road traffic injuries in children.

Methods Hospital based cross-sectional descriptive study was conducted during the period of September 2013 to August 2014 at ER, Yangon General Hospital to recognise epidemiological distribution of RTA among children under 12 years of age. During this period, 350 cases attended at ER and data were collected from out-patient register and police record from Yangon General Hospital. Three sub-groups were defined by type of injured persons; pedestrian, non-motor vehicle and motor vehicle. Children were grouped into 3 categories depending on their age.

Results Among the injured, 63.1\% were pedestrians, 277\% were motor vehicle accidents and only 9.15 were nno-motor vehicle accidents. Among the age group school going age were commonest with $68.9 \%$ with male preponderance $59.4 \%$ and most of them $(71.1 \%)$ were from urban area.

Head and neck injuries were most common with $54.9 \%$ followed by lower limb injuries (27.4\%) and upper limb injuries $(17.7 \%)$. Soft tissue injuries $(57.4 \%)$ were common followed by fractures $20 \%$. There were 4 deaths and the cause of death ws head injury and multiple injuries.

Conclusion Childhood road traffic injuries are common in school going age group and most of them are pedestrians. Road safety measures for children and school environment should be encouraged for possible interventions. Road Safety education should be introduced into curriculum and early childhood education on road safety should be delivered.

\section{IMPACT ANALYSIS OF REVISION OF A JAPANESE SAFETY STANDARD OF BICYCLE WHEEL GUARD}

\begin{abstract}
${ }^{1,2}$ Koji Kitamura, 1,2 Yoshifumi Nishida, ${ }^{1,2}$ Mikiko Oono, 1,2,3 Tatsuhiro Yamanaka. 'National Institute of Advanced Industrial Science and Technology, Japan; ${ }^{2}$ Safe Kids Japan; ${ }^{3}$ Ryokuen Children's Clinic, Japan.
\end{abstract}

\subsection{6/injuryprev-2016-042156.701}

Background We contributed to the revision of a Japanese safety standard of bicycle wheel guard for preventing childhood injury due to wheel spoke, by showing the actual situation of the injury based on our injury data and clarifying reachable range of child's foot based on experimental measurement. In this study, the purpose is to evaluate impact of the revision based on our injury database.

Methods Our injury data base includes injured body part data which is recorded as 3 dimensional area data on the 3 dimensional child model by our developed system. The system can calculate the frequency distribution by overlaying multiple data. To evaluate the impact, we compared probability distribution of injury cases due to bicycle before and after the revision.

Results The number of cases before the revision is 325 and the number of cases before the revision is 159 . We compared them by calculating injured probability distribution of body parts. As for all injury cases due to bicycle, injured probability of knees and heels is reduced after the revision. As for injury cases of foot which is injured due to wheel spoke, average of injured probability is decreased by approximately $55.3 \%$ after the revision. The result indicates that the revision is effective for preventing injury due to wheel spoke.

Conclusions We evaluated impact of the revision at this time. We showed that we can evaluate impact of preventive measure quantitatively based on injury database. We think that the impact will increase because bicycle which is fulfilled the revised safety standard will become widespread over time. We will continue to 